\title{
Arteriyel Hipertansiyon Tanısında Hasta Eğitim Düzeyi ve Aile Hekimliği Uygulamasının Rolü
}

\author{
The Role of Patient Training Level and Family Medicine \\ Administration in The Diagnosis of Arterial Hypertension
}

\section{Mahmut Altuntaş}

40 nolu Aile Sağlığı Merkezi, Konya, Türkiye

Gelis Tarihi/Received: 27 Eylül 2018 Kabul Tarihi/Accepted: 11 Aralık 2018

Yazışma Adresi: Mahmut Altuntas, MD. Aile Hekimliği, Konya, Türkiye

e-posta: draltuntas73@yahoo.com

\section{ORCID}

Mahmut Altuntaş

https://orcid.org/0000-0001-7764-0071

\section{Öz}

Amaç: Hipertansiyon (HT), başta kalp damar hastalıkları olmak üzere birçok ciddi hastalıkta risk faktörüdür. HT tanısının konulması pek çok kişide geç kalabilmektedir. Bununla birlikte birinci basamakta aile hekimliğinin günlük pratiğinin oldukça önemli bir kısmını oluşturan ve önlenebilir bir halk sağlığı sorunudur. Çalışmamızda, aile hekimliği uygulamasının, arteriyel hipertansiyon tanısı konulmasındaki etkinliği araştırılmıştır.

Hastalar ve Yöntem: 2017-2018 tarihleri arasında retrospektif olarak aile hekimliği birimimizde verilerine ulaşılabilen ve kesin kayıtları mevcut 18 yaş ve üzerindeki HT hastaları çalışmaya dahil edildi. Kişisel bilgiler (yaş, cinsiyet ve eğitim düzeyi) ve hastalık tanımlama bilgilerini (kaç yıldır hipertansiyon tanısı aldığı, başlangıç semptomu, hipertansiyon tanısı ilk nerede ve nasıl konulduğu) içeren toplamda yedi soruya verilen cevaplar Aile Hekimliği Bilgi Sisteminden retrospektif olarak incelendi.

Bulgular: 178 kadın, 108 erkek toplam 286 hasta tespit edildi. Araştırmaya katılanların \%5,9'u okur-yazar olmayan kesim, \%94,1 okur yazar kesimdi. Okur yazar hastaların eğitim düzeyleri; \%59,8 'i ilköğretim, $\% 10,5$ 'i lise ve $\% 16,8$ 'i lisans üzeri olarak tespit edildi. Araştırmaya katılanların \% 7.7'si aile hekimliği polikliniğinde, geri kalan \% 92.3'ü ise aile hekimliği dışında ikinci basamak sağlık kuruluşlarında ve diğer yerlerde tanı almışlardı. Eğitim düzeylerine göre \%7,7'si aile hekimliğinde, \% 92.3'ü ise aile hekimliğ dışında ikinci basamak sağlık kuruluşlarında ve diğer yerlerde arteriyel hipertansiyon için tanı almışlardı. Sonuç: Çalışmamızda; arteriyel hipertansiyon tanısı olan hastaların, eğitim düzeyleri ne olursa olsun, ikinci basamak sağlık kuruluşlarında daha sık tanı aldıkları tespit edildi. Konya ilimizde aile hekimliğ uygulamasının başlamasından sonra, birinci basamakta arteriyel hipertansiyon tanısı alma oranı \% 1,5 'ten \%16,3 gibi bir oranda artmış olmasına karşın aile hekimliği uygulamasının arteriyel hipertansiyon tanısı alma üzerine rolünün daha da arttırılması gerektiğini düşünüyoruz.

Anahtar Kelimeler: Arteriyel hipertansiyon tanısı, hasta eğitim düzeyi, Aile Hekimliği uygulaması

\section{Abstract}

Aim: Hypertension (HT) is a controllable and preventable public health problem that is a risk factor for many serious diseases, especially cardiovascular diseases. Hypertension, which can be silent and lethal, can not be diagnosed in many people. HT constitutes a significant part of the daily practice of the primary care physician. Today, the Family Medicine is a medical discipline constitutes the first level of the health system in Turkey. In our study, the effectiveness of family medicine practice in the diagnosis of arterial hypertension was investigated.

Patients and Methods: We retrospectively reviewed the data of the patients aged 18 years and olde who had access to their data in our family medicine department between 2017-2018. A total of seven questions, including personal information (age, gender and education level) and disease identification information (how many years were diagnosed with hypertension, baseline symptom, where and how the diagnosis of hypertension was first established) were retrospectively reviewed from the Family Medicine Information System.

Results: A total of 286 patients, 178 female and 108 male were detected. $9 \%$ of the participants were illiterate while $94.1 \%$ were literate. $59.8 \%$ of the illiterate patients were in primary education, $10.5 \%$ in high school and $16.8 \%$ in graduate education. $7.7 \%$ of the participants were diagnosed in the family medicine polyclinic, and the remaining $92.3 \%$ were diagnosed in secondary health care facilities and other places except family medicine. According to education level, $7.7 \%$ were diagnosed in family medicine and $92.3 \%$ were diagnosed in second-level health facilities and elsewhere except family medicine.

Conclusion: In our study; patients with arterial hypertension were diagnosed more frequently in secondary health care institutions regardless of their education level. Although the rate of diagnosis of arterial hypertension was increased from $1.5 \%$ to $16.3 \%$ in primary care after starting the practice of family medicine in Konya, we believe that the role of family medicine practice on the diagnosis of arterial hypertension should be increased even more.

Key words: Diagnosis of arterial hypertension, patient education level, family medicine practice
Atıf yapmak için: Altuntas M. Arteriyel Hipertansiyon Tanısında Hasta Eğitim Düzeyi ve Aile Hekimliği Uygulamasının Rolü. Selcuk Med J 2019;35(1): 31-36
Açıklama: Yazar bu makalede bahsedilen herhangi bir ürün, aygıt veya ilaç ile ilgili maddi çıkar ilişkisine sahip değildir. Araştırma, herhangi bir dış organizasyon tarafından desteklenmedi. Yazar calısmanın birincil verilerine tam erişm izni vermek ve derginin talep ettiğ takdirde verileri incelemesine (n) izin vermeyi kabul etmektedir. 


\section{GíRiş}

Hipertansiyon, başta kalp damar hastalıkları olmak üzere birçok ciddi hastalığın risk faktörü olup kontrol edilebilir ve önlenebilir bir halk sağlığı sorunudur. Hipertansiyon tanısı pek çok kişide teşhis eedilememekte yada geç kalınmaktadır. Erken tanı ve etkin müdahaleyle, hipertansiyonun kontrolü sağlanabilmekte ve böylece ekonomik olarak önemli kazançlar elde edilebilmektedir (1).

Mortalite ve morbite üzerinde oldukça önemli etkileri olmakla birlikte birinci basamakta da günlük pratiğinin oldukça önemli bir kısmını oluşturmaktadır. Olguların \%95'ini Esansiyel HT, diğer tüm nedenler de $\% 5$ 'lik bölümünü oluşturmaktadır(2).

Aile hekimliği, birinci basamak bir tıp disiplinidir (3). Dünya Aile Hekimleri Birliği'nin (WONCA) tanımına göre; Aile Hekimliği sağlık sisteminde ilk tıbbi temas noktasını oluşturarak, yaş, cinsiyet ya da kişinin tüm sağlık sorunlarıyla ilgilenir. Bu bağlamda bütüncül, kapsamlı ve koordineli bir bakım sağlayarak özgün görüşme süreci ve problem çözme becerileri ile bireye, ailesine ve topluma yönelik bir yaklaşım geliştirir (4)

Ülkemizde, aile hekimliği pilot uygulaması ilk Düzce ilimizde başlamıştır. Günümüzde halen 81 ilimizde birinci basamakta aile hekimliği uygulanmaktadır (5). Aile hekimliği uzman sayısı yetersiz olması nedeniyle, aile hekimliği uygulamasına, kısa süreli eğitimden geçirileren mevcut pratisyen hekimler ile başlanmıştır (6).

Sağlık sistemimizde hastanın ilk karşılaştığı kişi olan aile hekiminin eğitimi oldukça önemlidir. Aile hekimi, hastanın güncel izlem, korunma, tedavi ve takip protokollerini uygulayabilecek, gerekirse diğer branş uzmanı ve/veya hastaneye sevkini yapabilecek ve birinci basamağın intiyaçları doğrultusunda gerektirdiği gibi multi-disipliner bir yaklaşımla araştırmalar yapıp yürütebilecek vasıfta olmalıdır (7). Dünya Sağlık Örgütü, birinci basamak sağlık hizmetlerinin daha etkin olmasıyla hipertansiyon ile daha etkin mücadelede sağlanacağına dikkat çekmiş, sağlık çalışanlarının toplumda farkındalık sağlama, risk faktörlerine yönelik eğitim düzenleme gibi etkinliklerde aktif rol alması gerekliliği üzerinde durmuştur(8).

Çalışmamızda, bir birinci basamak tıp disiplini olan aile hekimliği uygulamasının başlaması ile birlikte, arteriyel hipertansiyon tanısı konulması üzerindeki etkinliği araştırılmıştır.

\section{HASTALAR VE YÖNTEM \\ Araştırmanın Örneklemi}

Tanımlayıcı tipte tasarlanan bu araştırma, Konya/ Meram 40 No'lu Aile Sağlığı Merkezinde 2017-2018 tarihleri arasında bir yıllık geriye dönük bir tarama yapılarak gerçekleştirildi. Aile hekimliği bilgi sistemine kesin kayıtlı 3500 hasta içerisinde hipertansiyon tanısı almış 523 hasta tarandı. Bu hastalardan, bilişsel düzeyi ile ilgili bir sorunu olmayan, aile hekimliğimiz bilgi sisteminde ayrıntılı öyküsü bulunan, kesin kayıtları mevcut 18 yaş ve üzerindeki 286 kişi çalışmaya dahil edildi.

\section{Veri Toplama}

Hipertansiyon tanısı alan bireyleri kapsayan 7 soruya cevap aranarak, bireylerin kişisel bilgileri ve hastalık tanımlama bilgileri iki bölümde incelendi. Kişisel bilgiler bölümü "yaş, cinsiyet ve eğitim düzeyini belirten üç soru, hastalık tanımlama bilgileri ise kaç yıldır hipertansiyon tanısı aldığı, başlangıç semptomu, hipertansiyon tanısı ilk nerede ve nasıl konulduğunu içeren dört sorudan oluşmaktaydı. Verilen cevaplar Aile Hekimliği Bilgi Sisteminden geriye dönük incelenerek yapıldı.

\section{İstatistiksel Analiz}

Araştırmadan elde edilen veriler SPSS (Statistical Package For Social Sciences) 20.0 programı ile değerlendirildi. Elde edilen verilere ait tanımlayıcı

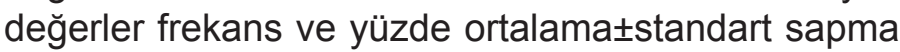
olarak hesaplandı. Kategorik yapıdaki özellikler bakımından grupların karşılaştırılmasında kikare testi, ölçümle belirtilen özellikler bakımından karşılaştırmada ise iki bağımsız ortalama arasındaki farka ait t-testi kullanıldı ve $p<0.05$ istatistiksel olarak anlamlı kabul edildi.

\section{BULGULAR}

Çalışmaya \% 62,2 'si kadın (178), \% 37,8'i erkek (108) toplam 286 hasta dahil edildi (Tablo 1). \% 46,9'u 65 yaş üzeri \%53,1'i 65 yaş altı gruptu. \%5,9 okuryazar olmayan hastaydı. Okur-yazar \%7, ilköğretim $\% 59,8$, lise $\% 10,5$ ve lisans üzeri $\% 16,8$ olmak üzere toplamda \%94,1 okur-yazar olan gruptan oluşmuştu (Tablo 2). Hastaların \% 43'ü Konya ilimizde aile hekimliği uygulamasının başlamasından sonra 1 .

Tablo 1. Araştırmaya Katılanların Cinsiyet ile İlgili Bulguları

\begin{tabular}{cll}
\hline Cinsiyet & $\mathbf{n}($ sayı) & \%(yüzde) \\
\hline Kadın & 178 & 62,2 \\
Erkek & 108 & 37,8 \\
Toplam & 286 & 100,0 \\
\hline
\end{tabular}


Tablo 2. Araştırmaya Katılanların Öğrenim Durumlarına İlişkin Bulgular

\begin{tabular}{lll}
\hline Eğitim Düzeyi & $\mathbf{n}$ (sayı) & \%(yüzde) \\
\hline Okuryazar Değil & 17 & 5,9 \\
Okuryazar & 20 & 7,0 \\
ilköğretim & 171 & 59,8 \\
Lise & 30 & 10,5 \\
Lisans ve üzeri & 48 & 16,8 \\
Toplam & 286 & 100,0 \\
\hline
\end{tabular}

ve 8. yıllar arası, \%57'si ise ilimizde aile hekimliği uygulaması başlamadan önce arteriyel hipertansiyon tanısı almıştı (Tablo 3 ).

Hastaların \% 37,1'i en sık baş dönmesi yakınması ile, \%17,8'i ise hiçbir yakınması yok iken arteriyel hipertansiyon tanısı almıştı. \% 7,7' ne aile hekimliği polikliniğinde, geri kalan \% 92,3'üne ise aile hekimliği dışında ikinci basamak sağlık kuruluşlarında ve diğer yerlerde tanı konulmuştu (Tablo 4). \% 90,2'si 15 günlük ev veya ofis ölçümleri ile takiplerle, $\% 9,1^{\prime \prime} i$ ise 24 saatlik holter monitör takılarak tanı almıştı.

Araştırmada eğitim durumlarına bakıldığında, okuryazar olmayanların tamamı (\% 100) ikinci basamak ve diğer sağlık kuruluşlarında, okuryazar olanların \% 25'i aile hekimliği polikliniğinde, \% 75'i ise ikinci basamak ve diğer sağlık kuruluşlarında teşhiş edilmişti. İlköğretim düzeyindekilerin \% 7'si aile hekimliği polikliniğinde, \% 93'ü ikinci basamak diğer sağlık kuruluşlarında, lise mezunu olanların \% 3,3'ü aile hekimliği polikliniğinde, \% 96,7'i ikinci basamak ve diğer sağlık kuruluşlarında, lisans ve üzeri eğitim düzeyi olanların \% 8,3'ü aile hekimliği polikliniğinde, \% 91,7'si ikinci basamak ve diğer sağlık kuruluşlarında tanı almışlardı. Sonuç olarak; eğitim düzeylerine göre \%7,7'si aile hekimliğinde \% 92,3'ü ise aile hekimliği dışında ikinci basamak sağlık kuruluşlarında ve diğer yerlerde arteriyel hipertansiyon için tanı almışlardı. (Tablo 5).

İlimizde aile hekimliğinin başlamasıyla tanı alma yılı 1-8 yıl arasında olanların \% 16,3'ü aile hekimliği polikliniğinde, \% 83,7'si ikinci basamak sağlık kuruluşları ve diğerlerinde teşhiş edilirken, aile hekimliği başlamadan önce tanı alma yılı 9-20 yıl

Tablo 3. Araştırmaya Katılanların tanı alma yılı ile İlgili Bulguları

\begin{tabular}{lll}
\hline Tanı Alma Yılı & n (sayı) & \% (yüzde) \\
\hline $1-8$ yıl & 123 & 43 \\
$9-20$ yıl & 137 & 47,9 \\
21 yıl ve üzeri & 26 & 9,1 \\
Toplam & 286 & 100,0 \\
\hline
\end{tabular}

Tablo 4. Araştırmaya Katılanların HT Tanısı İlk Nerede Konulmuş ile İlgili Bulguları

\begin{tabular}{lll}
\hline $\begin{array}{l}\text { HT Tanısı İlk } \\
\text { Nerede Konulmuş }\end{array}$ & $\mathbf{n}$ (sayı) & \% (yüzde) \\
\hline Aile Hekimliği & 22 & 7,7 \\
Acil Polikliniği & 36 & 12,6 \\
Dahiliye Polikliniği & 121 & 42,3 \\
Kardiyoloji Plokliniği & 79 & 27,6 \\
Nöroloji Polikliniği & 6 & 2,1 \\
Eczane & 2 &, 7 \\
Evde Kendi Kendine & 7 & 2,4 \\
Sağlık Ocağı & 13 & 4,5 \\
Toplam & 286 & 100,0 \\
\hline
\end{tabular}

arasında olanların \% 1,5'i sağlık ocağı polikliniğinde, \% 98,5'i ikinci basamak sağlık kuruluşları ve diğerlerinde, 21 yıl ve üzeri tanı yılı olanların, \% 100'ü ikinci basamak sağlık kuruluşları ve diğerlerinde arteriyel hipertansiyon tanısı almıştı (Tablo 6).

\section{TARTIŞMA}

Birinci basamakta çalışan hekim ve diğer sağlık ekibinin kardiyovasküler veya diğer kronik hastalıkların önlenmesinde büyük önemi vardır. Riskli bireylerin belirlenerek erken tanı ve tedavinin uygulaması olası komplikasyonların azaltılmasını sağlar (9).

Dünya Sağlık Örgütü, Türkiye'deki bulaşıcı olmayan hastalıklarla ilgili 2014 tarihinde "Bulaşıcı Olmayan Hastalıklarda Daha İyi Sonuçlar: Sağlık Sistemi İçin Zorluklar ve Fırsatlar" başlıklı rapor değerlendirmesi yapmıştır. Bu raporda;

Kardiyovasküler hastalıklar $(\mathrm{KVH})$ ve diyabet yönetimi için, ülkemizde aile hekimliğin güçlendirilmesi gerektiği ancak aile hekimlerinin $\mathrm{KVH}$, hipertansiyon, yüksek kolesterol, diyabet gibi risk faktörlerinin tansınıda ve takibinde halen sistematik olarak tam yer almadığı, bu hastalıklara yönelik taramaların etkin ve düzenli olmadığı, hastalıkların teşhisinin ikinci basamakta uzman doktorlar tarafından koyulup doğrulandığı ve kronik vakaların yönetiminin de genellikle uzman hekimler tarafından yapıldığı vurgulanmaktadır.

Aile hekimlerinin, bu tür hastalarda klinik karar verme süreçlerini destekleyecek uygulama kılavuzları ve görsel araçları bulunmamakta ve aile hekimleri ile uzman doktorlar arasında sistemik bir koordinasyon ve bilgi aktarımı bulunmadığından bahsedilmektedir.

Bununla birlikte bazı önerilerden bahsedilmektedir. Söz konusu KVH vakaların uzman hekimlerce teşhis edilip takibinin başta cazip görünebileceği fakat toplumun sağlığı yönünden uzun soluklu ve etkin bir 
Tablo 5. Araştırmaya Katılanların eğitim düzeyi ve tanı aldıkları birinci basamak aile hekimliği ve ikinci basamak sağlık kurumları ve diğerleri arasındaki ilişki

\begin{tabular}{llll}
\hline Eğitim düzeyleri & \multicolumn{2}{c}{ TANI YER } & Toplam \\
& Aile hekimliği $\mathbf{n}(\%)$ & 2. basamak ve diğer $\mathbf{n ( \% )}$ & \\
\hline Okur-yazar değil & $0(0,0 \%)$ & $17(100,0 \%)$ & $17(100,0 \%)$ \\
Okur-yazar & $5(25,0 \%)$ & $15(75,0 \%)$ & $20(100,0 \%)$ \\
ilköğretim & $12(7,0 \%)$ & $159(93,0 \%)$ & $171(100,0 \%)$ \\
Lise & $1(3,3 \%)$ & $29(96,7 \%)$ & $30(100,0 \%)$ \\
Lisans ve üzeri & $4(8,3 \%)$ & $44(91,7 \%)$ & $48(100,0 \%)$ \\
\hline
\end{tabular}

sonuç oluşturmak için en uygun yöntem olmadığı vurgulanmaktadır. $\mathrm{Bu}$ hastaların polikliniklerde uzman hekimlerce takibi, muhtemelen, $\mathrm{KVH}$ ve diyabet hastalarının geç dönemde teşhis edilmesine ve medikal tedavinin daha ağırlıklı olmasına sebep olacaktır.

Ancak toplum sağlığı merkezleri ve destek merkezleriyle yakın ilişki içinde aile hekimliği, KVH risk faktörlerinin sistematik bir şekilde taranması ve riskli davranışların (diyet, sigara içme vs.) değiştirilmesinde çok etkin olabilir, böylece kronik hastalığın morbiditesi önlenebilir. Aile hekimlerinin KVH vakalarının teşhisi ve takibinde daha fazla yer almasının sağlanması, risklerin sınıflandırıldığı bir yaklaşım benimsenmesi; böylece birçok vakanın aile hekimlerince teşhis edilip yönetilmesini vurgulanmaktadır. Böyle bir uygulama ise, uzman hekimlerin basit vakalar yerine daha karmaşık vakalara yoğunlaşmasını sağlayacaktır.

$\mathrm{Bu}$ raporda yer alan önerilerden yola çıkılarak 3 Kasım 2014 tarihinde Türkiye Halk Sağlığı Kurumu tarafından "Birinci Basamak Sağlık Hizmetlerinde Kardiyovasküler Risk Değerlendirmesi Çalışma Toplantısı" yapılmış olup, bu konuda birinci basamak sağlık hizmetlerinin kardiyovasküler riskleri değerlendirmesi ve hastaların risk profilinin saptanması ve her hastanın risk durumuna göre standart bir yaklaşımın sağlanması için çalışmalar başlatılmıştır(10).

Çalışmamızda KVH olan hipertansiyon tanısı olanların \% 7,7'si aile hekimliği polikliniğinde, geri kalan \% 92,3'ü ise aile hekimliği polikliniği dışında ikinci basamak sağlık kuruluşlarında ve diğer yerlerde tanı almışlardır (Tablo 6). Bu durumun, ülkemizde birinci basamak sağlık hizmetlerinde gerekli hasta sevk zincirinin kurulamamış olmasından kaynaklandığı kanaatindeyiz. Bu nedenle hastaların büyük çoğunluğu doğrudan hastanelere başvurmaktadırlar. Aslında vakaların büyük bir çoğunluğunun birinci basamakta sonuçlandırılıp az bir kısmının ikinci basamak sağlık kuruluşlarına sevk edilmesi gerekirken günümüzde hastalar doğrudan hastaneye başvurabilmekte ve bunun neticesinde gereksiz yoğunluk ve hasta bekleme sıraları oluşmaktadır.

Aile hekimliğinin birincil hedefi; birinci basamak sağlık hizmetlerini, en yüksek kalitede vermek ve buna toplumun katılımını da sağlamaktır. Ayrıca, kişilerin yaşadığı ve çalıştığı ortamlarda önleyici, teşhiş ve tedavi edici özellikleri bulunmaktadır. Birinci basamak sağlık hizmetleri devamlı olarak yaygın eğitimlerle geliştirilmelidir. Kişilerin intiyaçları da gözönünde bulundurularak koruyucu sağlık sistemi ön planda tutulmalı ve gerektiğinde sevk zinciri sistemi uygulaması yapılmalıdır.

Yapılan bir çalışmada eğitim seviyesi düşük olan HT hastalarının, hipertansiyon hakkında bilgi düzeylerinin de düşük olduğu ve katılımcıların \% 50'sinin hastalığının kontrol altında olmadığı bulunmuştur (11).

Çalışmamızda, eğitim durumlarına göre okuryazar olmayanların \% 100'ü ikinci basamak ve diğer sağlık kuruluşlarında, okuryazar olanların \% 25'i Aile Hekimliği polikliniğinde, \% 75'i ikinci basamak ve

Tablo 6. Araştırmaya katılanların tanı alma yılı ve tanı aldıkları birinci basamak aile hekimliği ve ikinci basamak sağlık kuruluşları ve diğerleri arasındaki ilişki

\begin{tabular}{llll}
\hline TANI ALMA YILI & \multicolumn{2}{c}{ TANI YERI } & Toplam \\
& Aile hekimliği n(\%) & 2. basamak ve diğer n(\%) & \\
\hline $1-8$ yıl & $20(16,3 \%)$ & $103(83,7 \%)$ & $123(100,0 \%)$ \\
$9-20$ yıl & $2(1,5 \%)$ & $135(98,5 \%)$ & $137(100,0 \%)$ \\
21 yıl veüzeri & $0(0,0 \%)$ & $26(100,0 \%)$ & $26(100,0 \%)$ \\
Toplam & $22(7,7 \%)$ & $264(92,3 \%)$ & $286(100,0 \%)$ \\
\hline
\end{tabular}


diğer sağlık kuruluşlarında tanı almıştır. İlköğretim düzeyindekilerin \% 7'si aile hekimliği polikliniğinde, \% 93'ü ikinci basamak diğer sağlık kuruluşlarında, lise mezunu olanların \% 3,3'ü Aile hekimliği polikliniğinde, \% 96,7'i ikinci basamak ve diğer sağlık kuruluşlarında, lisans ve üzeri eğitim düzeyi olanların \% 8,3'ü aile hekimliği polikliniğinde, \% 91,7'si ikinci basamak ve diğer sağlık kuruluşlarında tanı almışlar. $\mathrm{Bu}$ durum aile hekimliği uygulamasının ilimizde başlamasıyla bireylerin eğitim düzeyleri ile aile hekimliği uygulamasının hastalık üzerindeki rolünün az ve yetersiz olduğunu göstermektedir.

Birinci basamak sağlık hizmetlerinde hekim, hastanın hangi durumlarda, hangi uzman doktora gideceğini belirlemelidir. Gereksiz sevklerden sakınır ve sevk gerektiğinde ise hastanın sevki sonrası tanı ve tedavisini takip etmelidir. Bu dönemde sağlık hizmetleri arasında koordinasyon sağlar ve bu sayede hastaların uzman hekim kaynağını kullanmalarına klavuzluk eder. $\mathrm{Bu}$ kurulan denge sayesinde birinci, ikinci ve üçüncü basamak sağlık hizmetleri arasındaki gereksiz enerji ve zaman kaybı önlenmiş olur (6). Bizim çalışmamızda araştırmaya dahil edilenlerin tanı alma yılı 1-8 yıl arasında olanların \% 16,3'ü aile hekimliği polikliniğinde, \% 83,7'si ikinci basamak sağlık kuruluşları ve diğerlerinde, arteriyel hipertansiyon tanısı almışlardır. Bu durum yukarıda bahsi geçen birinci basamak ve ikinci basamak hizmetler arasında koordinasyonun olması gerektiğini destekler niteliktedir.

Türkiye' de, 15 ve daha üzeri yaştaki kişilerin \%13,2'si hipertansiyon hastalığına yakalanma riski taşımaktadır. Ülkemizde hipertansiyon hastalarının \%53' ü, orta yaş grubundadır, otuz yaş altında görülen hipertansiyon sıklığı \%12'dir (12). Elli yaş üzerinde oran belirgin olarak daha yüksek olup \%45-50' lerde iken altmış yaş sonrsında prevalansı \%60-80'lere ulaşmaktadır (13). Bizim çalışmada katılanların \% 46,9'u 65 yaş üzeri \%53,1'i 65 yaş altı gruplardan oluşmuştur. Bu da yukarıda bahsi geçen çalışmaları destekler niteliktedir.

Dünyada, hipertansiyon hastalarının çoğunun farkındalıklarının yetersiz olduğu, düzenli tedavi ve takiplerinin olmadığı ve tansiyon kontrolünün yeterli olmadığı bilinmektedir. (14). Çalışmamızda hastaların \% 90,2'sinin 15 günlük ev veya ofis ölçüm takipleri ile, \% 9,1'inin 24 saatlik holter monitör takılarak tanı aldığı tespit edildi. \% 37,1 hastada en sık baş dönmesi yakınması ile, \%17,8'inde ise hiçbir yakınması yok iken arteriyel hipertansiyon tanısı aldığı belirlendi.

Henüz yüksek kan basıncının farkında olmayan birçok kişi vardır. Hipertansiyonda kontrolü artırmak için birinci basamakta düzenli takip, ilaç düzenlemesi ve yaşam tarzı düzenlemesi yapılmalıdır. Durum farkındalığı artırmak için hipertansiyon taramaları yapılmalı, yüksek kan basıncı hakkında insanlar bilinçlendirilmeli ve kendi kendine kan basıncı ölçüm teknikleri öğretilmelidir.

\section{SONUÇ}

Sonuç olarak, çalışmamızda arteriyel hipertansiyon tanısı olan hastaların, eğitim düzeyleri ne olursa olsun birinci basamak aile hekimliğinde tanı almadan ziyade ikinci basamak sağlık kuruluşlarında daha sık tanı aldıkları tespit edildi. İlimizde aile hekimliği uygulaması başladıktan sonra birinci basamakta arteriyel hipertansiyon tanısı alma oranı \%1,5'ten \%16,3' e çıkmıştır. Ancak aile hekimliği uygulamasının arteriyel hipertansiyon tanısı alma üzerindeki rolünün daha da arttırılarak etkin hale getirilmesi gerektiği kanaatindeyiz. Bu anlamda, hastaların kendi kalp ve genel sağlıklarını korumaya ve geliştirmeye yönelik farkındalıklarının arttırılması gerekmektedir. Birinci basamak çalışanları tarafından kardiyovasküler riski önlemeye yönelik projeler geliştirilmeli, kanıta dayalı olması açısından güncel kılavuzlar ışığında bireye özel KVH risk değerlendirmesi yapılmalı, SCORE (Systematic Coronary Risk Evaluation) ya da önerilen diğer risk değerlendirme sistemlerinden biri kullanılarak, risk düzeyineuygun sağlıkyönetimininAile Hekimliği Bilgi Sistemi'nde yer alması sağlanmalıdır. $\mathrm{KVH}$ riskini azaltmaya yönelik girişimler sürekli olarak yapılmalıdır. Özellikle değiştirilebilir risk faktörlerine yönelik olarak bireylere ve topluma sağlıklı beslenme, sigara bırakma, hipertansiyon yönetimi ve fiziksel aktivite danışmanlığı yapılmalıdır.

Çıkar Çatışması: Çalışmada herhangi bir çıkar çatışması yoktur.

Finansal Çıkar Çatışması: Çalışmada herhangi bir finansal çıkar çatışması yoktur.

Yazışma Adresi: Mahmut Altuntas, MD. Aile Hekimliği, Konya, Türkiye

Telefon: +90 5335534589 e-posta: draltuntas73@yahoo.com KAYNAKLAR

1. WHO. A global brief on hypertension. Geneva : Switzerland World Health Organization, 2013:8-14

2. Dosh MS, The treatment of adults with essential hypertension. J Fam Pract 2002;51(1):74-80.

3. Güler Ç, Akın L. Halk sağlığı temel bilgiler. Cilt III. Ankara: Hacettepe Yayınları;2012.

4. The European definition of general practice/family medicine. Leuven: European Academy of Teachers in General 
Practice;2005:6.

5. Özata M, Tekin F, Öztürk YE. Konya'daki aile hekimliği hizmetlerinin değerlendirilmesi. Selçuk Ün Sos Bil Ens Der 2016;(35):205-18.

6. Türkiye sağlıkta dönüşüm programı değerlendirme raporu (2003-2011), T.C. Sağlık Bakanlığı yayınları, Ankara, 2012: 106-17.

7. Aile doktorları için kurs notları. Ankara: Sağlık Bakanlığı; 2004:11-3.

9. Dağıstan A, Gözüm S. Determination and management of cardiovascular disease risk on primary health care centers. TAF Prev Med Bull 2016;15:575-82.

10. WHO. Better noncommunicable disease outcomes: Challenges and opportunities for health systems assesment guide. Copenhagen, Denmark World Health Organization 2014:19-21.
11. Pandit AU, Tang JW, Bailey SC, et al. Education, literacy and health:Mediating effects on hypertension knowledge and control, Patient educationan counseling 2009;75(3):381-5.

12. Hipertansiyon, T.C. Sağlık Bakanlığı Birinci Basamağa Yönelik Tanı ve Tedavi Rehberi 2003;37-44.

13. Çöl M, Özdemir O, Ocaktan ME. Park sağlık ocağı bölgesindeki 35 yaş üstü hipertansiflerde tedavi-kontrol durumları ve davranışsal faktörler. Ankara Üniversitesi Tıp Fakültesi Mecmuası 2006;59:144-50.

14. Abaci A, Oguz A, Kozan O, et al. Treatment and control of hypertension in Turkish population: A survey on high blood pressure in primary care (the TURKSAHA study), J Hum Hypertens 2006;20:355-61. 